\title{
Educational Protocol during Radiotherapy and Its Relation to Skin Toxicity and Self-esteem among Breast Cancer Patients
}

\author{
Hend Elham Mohammed ${ }^{1}$, Safaa Mohammed Zaki ${ }^{2, *}$ \\ ${ }^{1}$ Medical Surgical Nursing, Faculty of Nursing, Minia University, Egypt \\ ${ }^{2}$ Psychiatric and Mental Health Nursing, Faculty of Nursing, Minia University, Egypt \\ *Corresponding author: safaamazen31@yahoo.com
}

\begin{abstract}
Background: Acute skin toxicity is one of the most common side effects of breast cancer radiotherapy and these adverse events often negatively affect patient's self-esteem and willingness to continue the treatment. Aim of the study: assess the breast cancer patient's knowledge in relation to skin care during radiotherapy before the implementation of educational protocol and examine the effect of educational protocol on breast cancer patients' knowledge in relation to reducing skin reaction and improving self-esteem after the implementation of educational protocol. Subject and method: Quasi-experimental research design was utilized to achieve the aim of the study. Subject: A purposeful sample including (40) female adult patients were included in the current study. Setting: This study was carried out at oncology center in Minia city. Tools of data collection: Two scales were standardized and two tools were utilized to collect data: 1- Bio socio-demographic characteristics and structured interview schedule; 2- Educational proshour for instructions to reduce radiotherapy skin toxicity; 3- Common Toxicity Criteria-; 4- Rosenberg Self-Esteem Scale. Results: There were highly statistically significant differences among both study and control groups regarding their self-esteem and skin toxicity after educational protocol, there were a highest strong negative statistical significant correlation was found between skin toxicity and both knowledge and self-esteem scales among the study and the control group. Conclusion: the educational protocol reduced skin toxicity of radiotherapy in the study group and improves their self-esteem than control group. Recommendations: Based on the research findings the patients' health education about care radiation target area for breast cancer had a positive effect on patients' skin toxicity degree, design and implement an in-service training program for nursing staff about protocol that minimize radiotherapy skin toxicity.
\end{abstract}

Keywords: breast cancer, radiotherapy, skin toxicity, self-esteem

Cite This Article: Hend Elham Mohammed, and Safaa Mohammed Zaki, "Educational Protocol during Radiotherapy and Its Relation to Skin Toxicity and Self-esteem among Breast Cancer Patients." American Journal of Nursing Research, vol. 6, no. 5 (2018): 273-281. doi: 10.12691/ajnr-6-5-8.

\section{Introduction}

Breast cancer is the most commonly diagnosed cancer in women across the world. It is estimated that one out of every eight women would develop breast cancer at some point in their lives. Estimated that 1.4 million new cases per year and can cause for approximately 460 thousand deaths yearly worldwide [1]. Breast cancer is the most common type of cancer list as more than 255,000 new cases expected in the United States in 2017. Approximately 40,610 deaths among women and 460 men occur each year related to breast cancer. Then the next most common cancers are lung cancer and prostate cancer [2].

In Egypt, breast cancer is estimated to be the most common cancer among females it represents $37.7 \%$, constituted 12,621 new cases in 2008 . The ratio between incidence and mortality rate for breast cancer was poor $(1.9: 1)$ as estimated in many regional Egyptian cancer registries as well as in hospital-based frequencies [3], while accounting for $59.6 \%$ in 2012 about 18,660 new cases. So, it is a leading cause of cancer-related mortality accounting $21.6 \%$ of females' total deaths [4]. Radiotherapy (RT) is one of the standardized treatments for breast cancer and also the main point of this study. Radiotherapy uses high-energy X-rays or other types of radiation to kill cancer cells or to stop their growing. Patients undergoing RT to the intact breast or chest wall with or without regional lymph nodes typically receive 4-6 weeks of treatment, with radiation dermatitis which is the most anticipated common acute side effect [5].

Adjuvant radiation to the breast or chest wall after surgery for breast cancer is generally well tolerated, but acute skin toxicity is a common side adverse that affects patients' quality of life. Usually cancer patients are 
suffering from irritation, pain, itching, and peeling, but the most uncomfortable and disruptive treatment is progression to moist desquamation (MD). The risk of MD is highly variable depending on the radiation target (breast vs chest wall) as well as multiple patient and treatment factors.

High percent about $71 \%$ in the setting of post-mastectomy radiation therapy (PMRT) and range from $11 \%$ to $47 \%$ in the setting of breast conservation [6].

Self-esteem is defined as the respect of a person feel for herself/himself because of self-value and confidence. Cancer patients are characterized by low self-esteem, which is considered as a significant problem for these patients [7].

Self-esteem (SE) can be classified as high, average or low. Having high SE is feeling confidently adequate person for life, it is about a positive effect, about believing in one's own competence and value, to demonstrate an ability to deal with challenges and to be able to adapt more easily to a given situation. Have average $\mathrm{SE}$ is fluctuating between feeling adequate and inadequate, right or wrong as a person. Low SE is feeling oneself wrong as a person. The higher the SE, the better equipped a person who can deal with life's adversities and the more likely they are to succeed and maintain healthy relationships. Thus, the way one feels about oneself crucially affects all aspects of the life experiences. Self-esteem constitutes the key to the success or failure of a person and to understanding him/ herself and others. It also reflects the ability to cope with life's challenges, to respect and defend one's own interests and requirements [8].

However, it is necessary for cancer patients to pay attention to their health and to come for regular follow-up visits because of the long-term nature of the treatment and for the follow-up of the disease and also in order to reduce the expected side effects. Cancer patients are more sensitive to criticism, have feelings of worthlessness, inferiority, isolation, insecurity, rigidity, fear of the new, conformism and a defensive posture [9].

Previous studies concluded that nursing education for breast cancer patients and their families would improve their self-care behaviors, diminished anxiety, had a positive effect on their emotions and attitudes, help them prepare for the future, strengthened their ability to cope with treatment and adverse effects, increased their quality of life, decreasing symptoms and decrease the need for postoperative analgesia and duration of hospital stay while increasing patient satisfaction $[10,11]$.

\section{Significant of the Study}

Radiotherapy is an essential treatment for patients with cancer and is associated with a number of short-term and long-term side-effects. One of these side-effects is radiation-induced skin reaction, affecting up to $95 \%$ of patients receiving radiotherapy for their cancer Raymond $\mathrm{JC}$ et al. [12]. It is nesscary to reduce the caused damage as far as possible, nursing staff should follow standarized precuation to minimize further damage and promote effective healing, based on the previous studies finding, the present study carried out to invastigate effect of the educational protocol on reducing radiotherapy skin reaction and improving self-esteem.

\section{Aim of the Study is to}

- Assess the breast cancer patients' knowledge in relation to skin care during radiotherapy before the implementation of educational protocol.

- Examine the effect of educational protocol on breast cancer patients' knowledge in relation to reducing skin toxicity and improving self-esteem.

\section{Research Hypothesis}

Applying an educational protocol for reducing skin reaction toxicity during radiotherapy and improving self-esteem among breast cancer patients.

\section{Subjects and Methods}

\subsection{Research Design}

The quasi-experimental research design was utilized in the current study.

Setting:

The current study was carried out at oncology center in Minia city in outpatient radiotherapy clinic. It serves Minia governorate and it's distinct.

\subsection{Subjects}

A purposeful sample of (40) female adult patients participated in the current study, they were classified equally and alternatively into two equal groups $(n=20)$ for a control group and $(n=20)$ for study group. Both groups of the current study were selected according to the following inclusion criteria:

\subsection{Inclusion Criteria}

- Adult female (20 - 60 years).

- Conscious and oriented.

- Scheduled for receiving radiotherapy for at least one month (12 sessions).

- Free from chronic diseases such as cardiac, renal and diabetic diseases.

\subsection{Tools of Data Collection}

Two scales and two tools were utilized to collect pertinent data for this current study.

Tool 1: Bio socio-demographic characteristic and structured interview schedule. It was developed by the researcher after revising extensive literature review. It was collected at the first interview and it covers two main parts:

Part one: The socio-demographic data for the patient which includes (age, marital status).

Part two: The medical-surgical information data such as: (schedule of sessions of radiotherapy, Frequency of 
radiation session, duration of radiation therapy, time appear of skin toxicity signs and symptom.........etc).

\subsubsection{Scale 1: Common Toxicity Criteria}

These criteria used to evaluate patient's skin reaction toxicity after radiotherapy adopted from June, 1999 [13] Scoring system" no skin toxicity score" (0), while "faint erythema or dry desquamation" score(1), but "moderate to brisk erythema" score (2), "moderate edema" score (3) is given when confluent moist desquamation $\geq 1.5 \mathrm{~cm}$ diameter and not confined to skin folds and "pitting edema" score (4) Lastly "when death" score (5).

\subsubsection{Scale 2: Rosenberg Self-Esteem Scale}

This scale was applied to patients to assess patient's self- esteem. This scale Adopted from [14] Rosenberg (1965). It composed totally from 10 items measures positive feelings about the self-was answered by patients items $(1,2,4,6$, and 7) and measures negative feelings about the self- was measured by patients answering of items $(3,5,8,9$, and 10 which are reversed in valence). Scale rank for positive items (1, 2, 4, 6, and 7) from Strongly agree $=3$ to Strongly disagree $=0$. While Scale rank for negative items $(3,5,8,9$, and 10) Strongly agree $=$ 0 to Strongly disagree $=3$.

Scoring system for this scale calculated by the sum of patients positive and negative answering, it ranges from 0 to 30 when patients assessment range from (15 to 25 ) this mean patient has normal self-esteem, but when patient has scored below 15 this means has low self-esteem and higher than 25 scores until 30 scores indicate higher selfesteem.

Tool II: Educational prochour and booklet were prepared by the researcher based on the knowledge. It was also supplemented with information based on review of relevant literature about health instruction about how to reduce skin toxicity of breast cancer patient received radiotherapy through skin instruction during radiotherapy session and nutrition to enhance health skin.

\subsection{Validity of Tools}

Tools content validity was tested to identify the degree to which the used tools measure what was supposed to be measured. The developed tools were examined by a panel of three experts in the field of the study (Minia University). All jury members $(100 \%)$ agree that current study tools were valid and relevant with the aim of the study.

\subsection{Reliability of Tools}

Cronbach's alpha reliability test- retest for the Rosenberg Self-esteem Scale (RSS) range from 0.82 to 0.85 .

Cronbach's alpha reliability test-retest reliability for Common Toxicity Criteria (CTC) reliability is high (at least 0.70 ).

A pilot study was carried out on 6 patients (10\%) of the total sample to test feasibility, objectivity, and applicability of the tools. Those patients were excluded from the study.

\subsection{Ethical Consideration}

An official permission to conduct the study was obtained from the ethical committee of the faculty of nursing, dean of faculty of nursing, oncology institute director. Oral consents were obtained from subjects who were informed about the purpose, procedure, benefits, nature of the study, follow-up and she had the right to withdraw from the study at any time without any rationale. Confidentiality and anonymity of each subject were ensured through coding of all data and protecting the obtained data.

\subsection{Procedure}

The current study was conducted by preparing of different data collection tools, in addition obtaining formal paper agreement which was taken in duration of one month before conducting the study. Data collection was done through daily basis (3 days per week) at morning. The total data collection was collected over a period of eight months starting from April 2017 to November 2018.

Selected sample who admitted to outpatient radiotherapy department was informed by the researcher individually about purpose and nature of the study, then researcher obtained oral and written consent from those who accepted to participate in this study. The researcher started collecting data from control group firstly in four months by using the first tool (Bio socio-demographic characteristics) and the two study scales, and then collecting data from study group was started after finishing control group by using the first tool and the two scales.

Data collection for study sample was done in outpatient radiotherapy clinic for educational session and The total number of sessions for data collection \& educational session for the study group was 2-4 sessions. It's duration for both study groups was ranged from 20 to 30 minutes.

Educational program was applied by the researcher to the study group before radiotherapy session. Each session usually started by a summary of content of the pervious sessions and the objectives of the new one. Also, the researcher has given patients a photo brochure prepared by researcher after extensive literature review. It was included skin toxicity after radiotherapy, instruction regard skin care and precaution to prevent radiotherapy toxicity related to skin, healthy nutrition and steps to improve psychological health and self- esteem. Follow-up for all patients (study \&control) started immediately and after one month from radiotherapy through face to face interview to evaluate the extent of skin toxicity and their self-esteem.

\subsection{Statistical Analysis}

Data were summarized, tabulated, and presented using descriptive statistics in the form of frequency distribution, percentages, means and the standard deviations as a measure of dispersion. A statistical package for the social science (SPSS), version (20) was used for statistical analysis of the data, as it contains the test of significance given in standard statistical books. Numerical data were expressed as mean and SD. 


\section{Results}

Table 1 shows that the mean average age among study \& control group were similar constituted $40.0 \pm$ 10.81 years and $39.10 \pm 904$ years respectively. As regards marital status for both groups, the highest percentage among study and control groups were married constituted $(40 \% \& 60 \%)$ respectively. On the other hand, the table results found that the majority of the study sample (study and control group) was lived in rural area constituted $(90 \% \& 80 \%)$ respectively. In relation to their educational level $(50 \% \& 55.7 \%)$ respectively of the current study sample (study and control groups) were illiterate while most of them were occupied as employers.

Table 2 illustrates that more than half of the study sample was had frequency of radiation therapy session every weak for both group constituted (60\%). According to duration of radiation therapy, it was found that the majority of the study group received radiotherapy for 4-5 weak while half of control group has radiation therapy duration constituted (50\%). As regarding to chemotherapy combined with radiotherapy for both group constituted $(75$ \& 60\%); respectively. Lastly according to time of skin toxicity signs and symptom after radiotherapy session for both groups, the highest percentage among study group had suffered from skin toxicity after 2 weak constituted $(40 \%)$ while the majority of control group had suffered from skin toxicity after one weak constituted $(70 \%)$.

Table 3: This table illustrates that there is an increase in patients' knowledge among study group after application of educational protocol about radiation skin care compared to control group with statistical significant $p$ value $\left(0.05^{*}\right)$.

Table 4: It demonstrates that there patients' knowledge increased among study group after application of an educational protocol about nutrition compared to control group with statistical significant $\mathrm{p}$ value $\left(0.05^{*}\right)$.

Table 5: Demonstrates that breast skin toxicity degree of radiotherapy is decreased according to common toxicity criteria scoring in study group patients' less than control group. There was a statistical significant difference between study and control groups p value $(0.01 *)$.
Table 6 shows that the highest percentage $(60 \%)$ of study group had normal self-esteem after application of educational protocol, while reverse percentage (55\%) among control group had low self-esteem. There were highly statistically significant differences between both study and control groups regarding their self-esteem assessment.

Table 7 shows the difference between the patients' selfesteem regarding their personal characteristics. There was a significant statistical difference between self-esteem and demographic characteristic of the study group. It was observed that the lowest self- esteem was among 31:40 years, employed women, living in urban area, married and has secondary school and diploma.

Table 1. Frequency distribution of the Socio demographic characteristics for both study \& control groups subjects. $(n=40)$

\begin{tabular}{|c|c|c|c|c|}
\hline \multirow[t]{2}{*}{ Items } & \multicolumn{2}{|c|}{$\begin{array}{l}\text { Study group } \\
\qquad \mathrm{N}=20\end{array}$} & \multicolumn{2}{|c|}{$\begin{array}{c}\text { Control group } \\
\mathrm{N}=20\end{array}$} \\
\hline & $\mathrm{N}$ & $\%$ & $\mathrm{~N}$ & $\%$ \\
\hline \multicolumn{5}{|l|}{ Age: } \\
\hline 20:30 years & 2 & 10 & 1 & 5 \\
\hline $31: 40$ years & 8 & 40 & 10 & 50 \\
\hline $41: 50$ years & 7 & 35 & 7 & 35 \\
\hline $51: 60$ years & 3 & 15 & 2 & 10 \\
\hline Mean \pm SD & \multicolumn{2}{|c|}{$40.0 \pm 10.81$} & \multicolumn{2}{|c|}{$39.10 \pm 904$} \\
\hline \multicolumn{5}{|c|}{ Occupation: } \\
\hline House wife & 6 & 30 & 8 & 40 \\
\hline Employment & 14 & 70 & 12 & 60 \\
\hline \multicolumn{5}{|c|}{ Residence: } \\
\hline Rural & 18 & 90 & 16 & 80 \\
\hline Urban & 2 & 10 & 4 & 20 \\
\hline \multicolumn{5}{|c|}{ Marital status: } \\
\hline Single & 1 & 5 & 2 & 10 \\
\hline Widow & 2 & 10 & 3 & 15 \\
\hline Married & 8 & 40 & 12 & 60 \\
\hline Divorced & 9 & 45 & 3 & 15 \\
\hline \multicolumn{5}{|c|}{ Education level } \\
\hline Illiterate & 10 & 50 & 13 & 55 \\
\hline Read and write & 3 & 15 & 4 & 20 \\
\hline Secondary school and diploma & 7 & 35 & 5 & 25 \\
\hline
\end{tabular}

Table 2. Frequency distribution of both study \& control groups in relation to current radiation regimen assessment $(n=40)$

\begin{tabular}{|c|c|c|c|c|c|}
\hline & \multicolumn{4}{|c|}{ Groups } & \multirow{3}{*}{ P-value } \\
\hline & \multicolumn{2}{|c|}{ Study $(n=20)$} & \multicolumn{2}{|c|}{ Control $(n=20)$} & \\
\hline & $\mathrm{N} \%$ & & $\mathrm{~N}$ & $\%$ & \\
\hline \multicolumn{6}{|c|}{ Frequency of radiation session } \\
\hline Every 3 day & 4 & 20 & 6 & 30 & \multirow{3}{*}{$\mathrm{X} 2=0.860 .02 *$} \\
\hline Every weak & 12 & 60 & 12 & 60 & \\
\hline Every 2 weak & 4 & 20 & 2 & 10 & \\
\hline \multicolumn{6}{|c|}{ Duration of radiation therapy } \\
\hline From 4-5 week & 14 & 70 & 10 & 50 & \multirow{2}{*}{$\mathrm{X} 2=0.800 .05^{*}$} \\
\hline From 5-7 week & 6 & 30 & 10 & 50 & \\
\hline \multicolumn{6}{|c|}{ Chemotherapy combined with radiation therapy } \\
\hline Yes & 15 & 75 & 12 & 60 & \multirow{2}{*}{$\mathrm{X} 2=0.700 .06$} \\
\hline No & 5 & 25 & 8 & 40 & \\
\hline \multicolumn{6}{|c|}{ Time appear of skin toxicity signs and symptom } \\
\hline After a week & 7 & 35 & 14 & 70 & \multirow{2}{*}{$\mathrm{X} 2=0.85$} \\
\hline After 2 week & 8 & 40 & 4 & 20 & \\
\hline After one month & 5 & 25 & 2 & 10 & $0.05^{*}$ \\
\hline
\end{tabular}


Table 3. Frequency distribution of the patients' knowledge before and after application of an educational instruction about radiation skin area among both groups

\begin{tabular}{|c|c|c|c|c|c|c|c|c|c|}
\hline \multirow{4}{*}{ knowledge of breast skin care } & \multicolumn{4}{|c|}{ Gro } & \multicolumn{4}{|c|}{ ups } & \multirow{4}{*}{ P-value } \\
\hline & \multicolumn{4}{|c|}{ Study $(\mathrm{n}=20)$} & \multicolumn{4}{|c|}{ Control $(\mathrm{n}=20)$} & \\
\hline & \multicolumn{2}{|c|}{ Pre } & \multicolumn{2}{|c|}{ Post } & \multicolumn{2}{|c|}{ Pre } & \multicolumn{2}{|c|}{ Post } & \\
\hline & $\mathrm{N}$ & $\%$ & $\mathrm{~N}$ & $\%$ & $\mathrm{~N}$ & $\%$ & $\mathrm{~N}$ & $\%$ & \\
\hline \multicolumn{9}{|l|}{ Use soap with perfume } & \multirow{33}{*}{$\begin{array}{c}\mathrm{X} 2= \\
0.86 \\
0.05^{*}\end{array}$} \\
\hline Yes & 12 & 60 & 3 & 15 & 16 & 80 & 14 & 70 & \\
\hline No & 8 & 40 & 17 & 85 & 4 & 20 & 6 & 30 & \\
\hline \multicolumn{9}{|l|}{ Use perfume } & \\
\hline Yes & 14 & 70 & 6 & 30 & 14 & 70 & 9 & 45 & \\
\hline No & 6 & 30 & 14 & 70 & 6 & 30 & 11 & 55 & \\
\hline \multicolumn{9}{|c|}{ Use rigid towel to dry skin by fraction method } & \\
\hline Yes & 10 & 50 & 4 & 20 & 10 & 50 & 11 & 55 & \\
\hline No & 10 & 50 & 16 & 80 & 10 & 50 & 9 & 45 & \\
\hline \multicolumn{9}{|c|}{ Use cream or lotion in radiation area without doctor order } & \\
\hline Yes & 8 & 40 & 2 & 10 & 12 & 60 & 8 & 40 & \\
\hline No & 12 & 60 & 18 & 90 & 8 & 40 & 12 & 60 & \\
\hline \multicolumn{9}{|c|}{ Use cream or sweet to remove hair in radiation area } & \\
\hline Yes & 5 & 25 & 2 & 10 & 8 & 40 & 5 & 25 & \\
\hline No & 15 & 75 & 18 & 90 & 12 & 60 & 15 & 75 & \\
\hline \multicolumn{9}{|c|}{ Use razor to remove hair in radiation area } & \\
\hline Yes & 6 & 30 & 2 & 10 & 6 & 30 & 2 & 10 & \\
\hline No & 14 & 70 & 18 & 90 & 14 & 70 & 18 & 90 & \\
\hline \multicolumn{9}{|l|}{ Rub in radiation area } & \\
\hline Yes & 16 & 80 & 3 & 15 & 16 & 80 & 3 & 15 & \\
\hline No & 4 & 20 & 17 & 85 & 4 & 20 & 17 & 85 & \\
\hline \multicolumn{9}{|l|}{ Exposure to extreme heat or cold } & \\
\hline Yes & 8 & 40 & 1 & 5 & 8 & 40 & 4 & 20 & \\
\hline No & 12 & 60 & 19 & 95 & 12 & 60 & 16 & 80 & \\
\hline \multicolumn{9}{|c|}{ Wear woolen garments or industrial textiles } & \\
\hline Yes & 18 & 90 & 7 & 35 & 18 & 90 & 7 & 35 & \\
\hline No & 2 & 10 & 13 & 65 & 2 & 10 & 13 & 65 & \\
\hline \multicolumn{9}{|l|}{ Wear tight clothes } & \\
\hline Yes & 12 & 60 & 4 & 20 & 12 & 60 & 7 & 35 & \\
\hline No & 8 & 40 & 16 & 80 & 8 & 40 & 13 & 65 & \\
\hline \multicolumn{9}{|l|}{ Radiation area exposed to sun } & \\
\hline Yes & 6 & 30 & 1 & 5 & 6 & 30 & 4 & 20 & \\
\hline No & 14 & 70 & 19 & 95 & 14 & 70 & 16 & 80 & \\
\hline
\end{tabular}

Table 4. Frequency distribution of the patients' knowledge before and after application of an educational instruction about nutrition in both groups

\begin{tabular}{|c|c|c|c|c|c|c|c|c|c|}
\hline \multirow{4}{*}{ Knowledge about nutrition } & \multirow{2}{*}{\multicolumn{4}{|c|}{$\begin{array}{c}\text { Gro } \\
\text { Study }(\mathrm{n}=20) \\
\end{array}$}} & \multirow{2}{*}{\multicolumn{4}{|c|}{$\begin{array}{c}\text { ups } \\
\text { Control }(n=20)\end{array}$}} & \multirow{4}{*}{ P-value } \\
\hline & & & & & & & & & \\
\hline & \multicolumn{2}{|c|}{ Pre } & \multicolumn{2}{|c|}{ Post } & \multicolumn{2}{|c|}{ Pre } & \multicolumn{2}{|c|}{ Post } & \\
\hline & $\mathrm{N}$ & $\%$ & $\mathrm{~N}$ & $\%$ & $\mathrm{~N}$ & $\%$ & $\mathrm{~N}$ & $\%$ & \\
\hline \multicolumn{9}{|l|}{ Drink water 2-3 L/day } & \multirow{18}{*}{$\begin{array}{c}\mathrm{X} 2= \\
\cdot, 78 \\
0.05^{*}\end{array}$} \\
\hline Yes & 7 & 35 & 16 & 80 & 9 & 45 & 15 & 75 & \\
\hline No & 13 & 65 & 4 & 20 & 11 & 55 & 5 & 25 & \\
\hline \multicolumn{9}{|l|}{ Eating fresh fruit and vegetable } & \\
\hline Yes & 6 & 30 & 16 & 80 & 8 & 40 & 8 & \multirow{2}{*}{$\begin{array}{l}0 \\
0\end{array}$} & \\
\hline No & 14 & 70 & 4 & 20 & 12 & 60 & 12 & & \\
\hline \multicolumn{9}{|l|}{ Eating protein } & \\
\hline Yes & 4 & 20 & 10 & 50 & 7 & 35 & 15 & \multirow{2}{*}{5} & \\
\hline No & 16 & 80 & 10 & 50 & 13 & 65 & 5 & & \\
\hline \multicolumn{9}{|l|}{ Low fat diet } & \\
\hline Yes & 7 & 35 & 18 & 90 & 6 & 30 & 14 & 70 & \\
\hline No & 13 & 65 & 2 & 10 & 14 & 70 & 6 & 30 & \\
\hline \multicolumn{9}{|c|}{$\begin{array}{l}\text { Avoid eating before and after radiation } \\
\text { therapy session } 30 \text { minutes }\end{array}$} & \\
\hline Yes & 4 & 20 & 17 & 85 & 7 & 35 & 16 & 80 & \\
\hline No & 16 & 80 & 3 & 15 & 13 & 65 & 4 & 20 & \\
\hline \multicolumn{9}{|c|}{$\begin{array}{l}\text { voidance all stimulant for nausea and } \\
\text { vomiting at meal time }\end{array}$} & \\
\hline Yes & 5 & 25 & 18 & 90 & 10 & 50 & 13 & 65 & \\
\hline No & 15 & 75 & 2 & 10 & 10 & 50 & 7 & 35 & \\
\hline
\end{tabular}


Table 5. Frequency distribution of both study \& control groups as regarding their breast skin toxicity assessment (n= 40)

\begin{tabular}{|c|c|c|c|c|c|}
\hline \multirow{3}{*}{ Breast skin toxicity } & \multicolumn{4}{|c|}{ Groups } & \multirow{3}{*}{ P-value } \\
\hline & \multicolumn{2}{|c|}{ Study $(n=20)$} & \multicolumn{2}{|c|}{ Control $(n=20)$} & \\
\hline & $\mathrm{N}$ & $\%$ & $\mathrm{~N}$ & $\%$ & \\
\hline 0 - No visible change & . & 0 & 0 & 0 & \multirow{5}{*}{$\begin{array}{l}\mathrm{X} 2=0.60 \\
0.01 *\end{array}$} \\
\hline 1- Faint erythema or dry desquamation & 16 & 80 & 5 & 25 & \\
\hline $\begin{array}{l}\text { 2- Moderate to brisk erythema or a patchy moist desquamation, mostly confined } \\
\text { to skin folds and creases; moderate edema }\end{array}$ & 4 & 20 & 9 & 45 & \\
\hline $\begin{array}{l}\text { 3- Confluent moist desquamation } \\
\geq 1.5 \mathrm{~cm} \\
\text { diameter and not confined to skin folds; } \\
\text { pitting edema }\end{array}$ & 0 & 0 & 6 & 30 & \\
\hline $\begin{array}{l}\text { 4- Skin necrosis or ulceration of full thickness dermis; may include bleeding not } \\
\text { induced by minor trauma or abrasion }\end{array}$ & 0 & 0 & 0 & 0 & \\
\hline 5- death directly related to radiation effect & 0 & 0 & 0 & 0 & \\
\hline
\end{tabular}

Table 6. Frequency distribution of both study \& control groups as regarding their self-esteem assessment $(n=40)$

\begin{tabular}{|c|c|c|c|c|c|}
\hline \multirow{2}{*}{ Self-esteem } & \multicolumn{2}{|c|}{ Study $(n=20)$} & \multicolumn{2}{|c|}{ Control $(n=20)$} & \multirow{2}{*}{ P-value } \\
\hline & No. & $\%$ & No. & $\%$ & \\
\hline Higher self- esteem & 3 & 15 & 0 & 0 & \multirow{3}{*}{$\chi 2=0.750 .005^{*}$} \\
\hline Normal self esteem & 12 & 60 & 9 & 45 & \\
\hline Low self esteem & 5 & 25 & 11 & 55 & \\
\hline
\end{tabular}

Table 7. Difference between the Patients' self- esteem regarding their personal characteristics $n=40$

\begin{tabular}{|c|c|c|c|c|c|}
\hline \multirow{3}{*}{ Items } & \multicolumn{3}{|c|}{ Self esteem } & \multirow{2}{*}{ F.test } & \multirow{2}{*}{ P. value } \\
\hline & Higher self- esteem & Normal self esteem & Low self esteem & & \\
\hline & Mean \pm SD & Mean \pm SD & Mean \pm SD & \multirow{5}{*}{15.3} & \multirow{5}{*}{$0.04 *$} \\
\hline 20:30 years & $26.2 \pm 0.9$ & $17.2 \pm 0.2$ & $8.5 \pm 0.5$ & & \\
\hline $31: 40$ years & $28.3 \pm 0.8$ & $22.4 \pm 0.8$ & $12.4 \pm 0.2$ & & \\
\hline $41: 50$ years & $26.5 \pm 0.8$ & $19.3 \pm 0.7$ & $7.5 \pm 0.3$ & & \\
\hline 51:60 years & $27.2 \pm 0.9$ & $16.4 \pm 0.5$ & $10.3 \pm 0.5$ & & \\
\hline Occupation: & & & & \multirow{3}{*}{11.2} & \multirow{3}{*}{$0.03 *$} \\
\hline House wife & $26.5 \pm 0.8$ & $17.5 \pm 0.8$ & $12.4 \pm 0.6$ & & \\
\hline Employment & $27.2 \pm 0.9$ & $20.7 \pm 0.9$ & $14.5 \pm 0.7$ & & \\
\hline \multicolumn{4}{|l|}{ Residence: } & \multirow[b]{2}{*}{13.3} & \multirow[b]{2}{*}{$0.03 *$} \\
\hline Rural & $26.5 \pm 0.8$ & $18.4 \pm 0.9$ & $10.3 \pm 0.4$ & & \\
\hline \multicolumn{4}{|l|}{ Marital status: } & \multirow{5}{*}{10.5} & \multirow{5}{*}{$0.04 *$} \\
\hline Single & $26.5 \pm 0.8$ & $18.3 \pm 0.7$ & $12.5 \pm 0.5$ & & \\
\hline Widow & $26.5 \pm 0.8$ & $17.4 \pm 0.8$ & $7.2 \pm 0.3$ & & \\
\hline Married & $28.3 \pm 0.7$ & $23.5 \pm 0.9$ & $14.4 \pm 0.4$ & & \\
\hline Divorced & $27.2 \pm 0.8$ & $16.2 \pm 0.5$ & $7.2 \pm 0.3$ & & \\
\hline \multicolumn{4}{|l|}{ Education level } & \multirow{4}{*}{11.2} & \multirow{4}{*}{$0.05 *$} \\
\hline Illiterate & $26.5 \pm 0.5$ & $18.3 \pm 0.4$ & $10.6 \pm 0.4$ & & \\
\hline Read and write & $26.5 \pm 0.5$ & $20.2 \pm 0.7$ & $12.4 \pm 0.7$ & & \\
\hline Secondary school and diploma & $28.3 \pm 0.7$ & $23.4 \pm 0.8$ & $14.4 \pm 0.4$ & & \\
\hline
\end{tabular}

Table 8. Correlation between patients' knowledge, skin toxicity and self-esteem among study and control group

\begin{tabular}{|l|c|c|c|c|}
\hline \multirow{2}{*}{} & \multicolumn{3}{|c|}{ Skin toxicity } \\
\cline { 2 - 5 } & \multicolumn{2}{|c|}{ Study } & \multicolumn{2}{|c|}{ Control } \\
\cline { 2 - 5 } & $\mathrm{R}$ & $\mathrm{P}$ & $\mathrm{R}$ & .961 \\
\hline Knowledge & $0.945-$ & $.000^{* *}$ & $.000^{* *}$ & 0.90 \\
\hline Self-esteem & $0.88-$ & $0.001 * *$ & $0.005^{* *}$ \\
\hline
\end{tabular}

$* * \mathrm{p}=\leq .01$

Table 8 shows that, there was a highest strong negative statistical significant correlation between skin toxicity and both knowledge and self-esteem in both the study and the control group of breast cancer patients'. 


\section{Discussion}

The present study showed that, the mean average age among study\& control groups were similar constituted $40.0 \pm 10.81$ years and $39.10 \pm 904$ years. This result was in agreement with Mamdouh, et al. [15] who mentioned that distribution of breast cancer among Egyptian patients was occurring between 30-60 years of age. The median age at diagnosis is 49 years. In this respect, Farouk, et al. [16] noticed that the incidence of breast cancer increases with age and breast cancer in young women is considered aggressive and associated with a poor prognosis. They reported that an incidence $8.19 \%$ of participants were aged $<35$ years among 4,628 patients were diagnosed with breast cancer over 10 years (2006-2015) in the Oncology Center at Mansoura University in Egypt.

Howlader et al. [17] reported that the breast cancer is the second most common type of cancer in the United States, and over $89 \%$ of those patients diagnosed with breast cancer are surviving at least 5 years after diagnosis. In terms of younger women diagnosed with breast cancer, there are a growing number of younger women diagnosed, with an estimate of $33.6 \%$ of new cases per year in women 54 years and younger. The current study illustrated that more than half of the study sample had frequent radiation therapy session every week for both groups represents $(60 \%)$ and $(40 \%)$ of study group suffered from skin toxicity after 2 weeks, while the majority of control group had suffered from skin toxicity after one week (70\%). This result was supported by Patricia P, [18] who reported that the radiation therapy has terrified side effects specific to the part of the body being treated and generally begin after approximately 2 weeks of treatment.

The study finding revealed that there was an increase in patients' knowledge among study group after application of an educational protocol about radiation skin care compared to control group with statistical significant (0.05). This finding is in agreement with Maurene, [19] who reported that patients knowledge was increased after having educational program about skin care.

In addition, Sven D'haese, [20] reported that the skin care is needed during radiation therapy to prevent and treat radiation dermatitis. Applying of the skin care protocol id in this study has led to a statistically significant decrease in the level of skin toxicity. He mentioned that implementation of a skin care protocol enhanced standardization in Flanders, improved adherence to evidence based guidelines and lead to the disappearance of outdated ritualistic practices.

Results of the present study showed that there is an increase in patients' knowledge among study group after application of an educational protocol about nutrition compared to control group with statistical significant (0.05).

Regarding the effect of an educational protocol on skin toxicity, the current study revealed that there was a decrease in degree of breast skin toxicity of radiotherapy according to RTOG common toxicity criteria scoring in study group patients' less than control group. There was a statistical significant difference between study and control groups (0.01). This finding is compatible with Jieun et al.; [21] who reported that most of the breast cancer patients experience multiple symptoms associated with radiation dermatitis. Hyperpigmentation was the most common and uncomfortable symptom followed by erythema. Majority of patients wanted management for radiation dermatitis and patients who experienced dryness, burning feelings, irritation, roughness, and hyperpigmentation had higher needs for radiation dermatitis management.

In the same context, reported that 257 patients, 73 (28.4\%) experienced extensive moist desquamation, 84 (32.7\%) Common Terminology Criteria for Adverse Effects skin toxicity grade 3, and $57(22.2 \%)$ a pain impacting on daily life activities. Among symptoms only grade 3 moist desquamation was significantly associated with severe pain $(\mathrm{P}<.001)$. On multivariate analysis, smoking, high-energy photons, and skin bolus were significantly associated with severe moist desquamation. Skin toxicity doubled for smokers, with $40 \%$ severe pain, $48 \%$ grade 3 moist desquamation, and $64 \%$ grade 3 skin toxicity. Without skin bolus $4.2 \%$ had severe pain, none moist desquamation, and $2.1 \%$ grade 3 skin toxicity. When skin bolus was used on alternate days, the frequency increased to $15 \%$ for pain, $22 \%$ for moist desquamation, and $26 \%$ for grade 3 skin toxicity. When bolus was used daily, $32 \%$ had pain, $41 \%$ moist desquamation, and $47 \%$ grade 3 skin toxicity. Symptoms peaked 1 to 2 weeks after the end of PMRT.

Regarding the effect of skin toxicity on self-esteem, the current study revealed that the highest percentage $(60 \%)$ among study group was had normal self-esteem after they applied educational protocol, while reverse percentage (55\%) among control group had low self-esteem. There were highly statistically significant differences between both study and control groups regarding their self-esteem assessment (0.005).

This result is in agreement with Rosenberg et al., 2013 [14] who reported that many physical and psychological problems related to radiation therapy, these problems related to sexuality, including body image and related distress for this problem. Body image concerns in younger women have been attributed to loss of the breast from surgery, resulting scarring and physical changes resulting from adjuvant treatment, all of which can have an impact on overall quality of life and in particular, body image perceptions and self-esteem in younger women. Indeed, a research carried out with 48 women who went through breast cancer surgeries to analyze self-esteem, the authors found that most women (54.1\%) showed high self-esteem. accordingly with the findings of this study, which presented higher frequency of patients with high self-esteem. [22].

The same authors reported that it is worth mentioning that people with high self-esteem feel confident and appreciated, present positive feelings towards themselves, believe in their own competence, and feel capable of dealing with the imposed challenges and to adapt themselves to different situations. In this way, when people undergoing radiotherapy treatment present high self-esteem, it will be possible for them to see life in another way and consequently, to face the disease and the treatment differently from patients with low self-esteem.

In contrast, Bauer, et. al., [23] reported that many women experienced distress following breast cancer treatment and might have required referral for psychological 
assessment, management and long-term support. Women who experienced distress were more likely to be dissatisfied with the treatment decision. Indeed, Manne \& Badr [24] and Moreira \& Canavarr [25] reported that adjustments to treatment sequel can also have an impact on both partner and breast cancer patient, producing physical limitations. Adding to results the negative impacting of body image and sexual functioning in the patient and higher levels of psychological distress in partners of breast cancer patients In the present study, there was a significant statistical difference between selfesteem and demographic characteristic of the study sample. This result is not consistent with the result of Julia et, al., [26] who found that there was no significant effect of the sociodemographic variables age, marital status, educational level and work status on self-esteem of the studied sample. In the present study, It was observed that the lowest self-esteem was among 31:40 years, also, Carver et al., [27] found that breast cancer and its treatment have more of an impact on younger women. It is possible that this phenomenon is related to the life-cycle stage the patient is at.

In the present study, it was observed that the lowest self-esteem was among employed women, living in urban area and those married. However, Cordova [28] noticed that for the variables of employment, educational level, children, lives alone, amount of support received, and the analyses of variance yielded no significant effect in relation to self-esteem.

In contrast, Yurek, et, al., [29] point out that breast cancer patients who are single suffer specific stressors: pessimism regarding future relationships, negative body image and impaired sexuality, fear of disclosing illness to partners, pain of rejection by partners, sense of isolation and inadequate support. Although life-stages and the milestones that accompany them, such as marriage or committed long- term relationships, usually correspond to specific age brackets, in many cases it is not so. It could be argued that marital status or the corresponding life stage the patient is at, and not age itself, is what differentiates the experience of these women in regard to their body image. It is important to note as well that in various other studies of age showed no significant relationship to self -esteem.

The present study also found that there was a highest strong negative statistical significant correlation between skin toxicity and both knowledge and self-esteem scales among the study and the control group of breast cancer patients'. This can be interpreted as, when patients' knowledge increases, it can improve physical health which consequently increases psychological health and selfesteem.

\section{Conclusion}

The study findings concluded that the educational protocol about skin care of breast cancer patients who receive radiotherapy reduce skin toxicity in the study group therefore and improve their self-esteem. Results illustrated that there were statistically significant differences between study and control groups regarding skin toxicity degree and self-esteem.

\section{Recommendations}

- Based on the research findings the patients' health education about care radiation target area for breast cancer had a positive effect on patients' skin toxicity degree.

- Design and implement an in-service training program for nursing staff that illustrate purposes and benefits of an educational protocol to minimize radiotherapy skin toxicity.

\section{References}

[1] Brito CMM, Lourenção, Saul M, Bazan M, Otsubo PPS, Imamura M, et al. (2012). Breast cancer: rehabilitation. Acta Fisiatr.; 19(2): 66-72.

[2] American Cancer Society. (2017). Cancer Facts and Figures. Atlanta, Ga: American Cancer Society. Available from https://www.cancer.org/content/dam/cancer-org/research/cancerfacts-and-statistics/annual-cancer-facts-and-figures/2017/cancerfacts-and-figures-2017.pdf.

[3] Zeeneldin A, Mohamed Ramadan, Ayman Abdelsamee Gaber, Fatma Mohamed Taha. (2013). Clinico-pathological features of breast carcinoma in elderly Egyptian patients: A comparison with the non-elderly using population-based data. Journal of the Egyptian National Cancer Institute; 25, 5-11.

[4] World Health Organization (2014): Cancer Country Profiles. Available from

http://www.who.int/cancer/country- profiles/egy_en.pd.

[5] Adam J Kole, Lauren Kole, and Meena S Moran. (2017). Acute radiation dermatitis in breast cancer patients: challenges and solutions Breast Cancer (Dove Med Press).; 9: 313-323. PMCID: PMC5426474.

[6] Arti Parekh, Avani D. Dholakia, Daniel J. Zabranksy, Fariba Asrari, Melissa Camp, Mehran Habibi, Richard Zellars, Jean L. (2018). Wright, Predictors of radiation-induced acute skin toxicity in breast cancer at a single institution: Role of fractionation and treatment volume January-March, Volume 3, Issue 1, Pages 8-15 Advances in Radiation Oncology.

[7] Ozkan B, Mentes S, Ozturk A, Soyuer S. (2014). Effects of Follow-up by Phone Interview and Anger Management Training Provided to Patients with Breast Cancer Undergoing Radiotherapy on Levels of Self-Esteem, Anger and Depression. International Journal of Hematology and Oncology; 4(24): 260-9.

[8] Terra FS. (2010). Avaliação da ansiedade, depressãoe autoestima em docentes de Enfermagem deuniversidade pública e privada [tese]. Ribeirão Preto (SP): Universidade de São Paulo, Escola de Enfermagem de Ribeirão Preto.

[9] Nicolussi AC, Sawada NO. (2013). Qualidade de vida de pacientes com câncer de mama em terapia adjuvante. Rev Gaúcha Enferm. 2011 Dez; 32(4):759-66.Nursing: Research and Reviews: 3 47-57.

[10] Sharif F, Abshorshori N, Tahmasebi S, Hazrati M, Zare N and Masoumi S. (2010). The effect of peer-led education on the life quality of mastectomy patients referred to breast cancer-clinics in Shiraz, Iran 2009. Health Qual Life Outcomes. 8: 74. PMID: 20653966.

[11] Lei CP, Har YC, Abdullah KL (2011). Informational needs of breast cancer patients on chemotherapy: differences between patients' and nurses' perceptions. Asian Pac J Cancer Prev.; 12(3): 797-802.

[12] Raymond Javan Chan, Joan Webster, Bryan Chung, Louise Marquart, Muhtashimuddin Ahmed, and Stuart Garantziotis. (2014). Prevention and treatment of acute radiation-induced skin reactions: a systematic review and meta-analysis of randomized controlled trials

[13] June, (1999). Common Toxicity Criteria, Version 2.0 National Cancer Institution cancer therapy evaluation program.

[14] Rosenberg SM, Tamimi RM, Gelber S, (2013). Body image in recently diagnosed young women with early breast cancer. Psychooncology. Aug; 22(8): 1849-1855. [PMC free article] [PubMed]. 
[15] Mamdouh. H, El-Mansy. H, Ibrahim F. Kharboush, Ismail. H, May M. Tawfik, Abdel El-Baky. M, El Sharkawy. O (2014) Barriers to breast cancer screening among a sample of Egyptian females. Journal of Family and Community Medicine. 21(2): 119-124.

[16] Omar Farouk, Mohamed A Ebrahim, Ahmad Senbel, Ziad Emarah, Waleed Abozeed, Mohamed O Seisa, Summer Mackisack, Salah Abdel Jalil, and Safaa Abdelhady (2016). Breast cancer characteristics in very young Egyptian women $\leq 35$ years Breast Cancer (Dove Med Press).; 8: 53-58. Published online 2016 Apr 5.

[17] Howlader N, Noone AM, Krapcho M, Garshell J, Neyman N, Altekruse SF, Kosary CL, Yu M, Ruhl J, Tatalovich Z, Cho H, Mariotto A, Lewis DR, Chen HS, Feuer EJ, Cronin KA. (2010). Cancer Statistics Review, 1975. Bethesda, MD: National Cancer Institute; 2013. http://seer.cancer.gov/csr/1975_2010/.

[18] Patricia Poirier 2013: Nursing Research and Reviews Nursingled management of side effects of radiation: evidence-based recommendations for practice Dovepress submit your manuscript | www.dovepress.com Dovepress 47 Review open access to scientific and medical research.

[19] Maurene Mc. (2006). Evidence-Based Skin Care Management in Radiation Therapy Seminars in Oncology Nursing Volume 22, Issue 3, August, Pages 163-173.

[20] Sven D'haese .Marleen Van Roy, Trees Bate, Paul Bijdekerke, Vincent Vinh-Hung. (2009). Management of skin reactions during radiotherapy in Flanders (Belgium): Management of skin reactions during radiotherapy in Flanders (Belgium): A study of nursing practice before and after the introduction of a skin care protocol A study of nursing practice before and after the introduction of a skin care protocol Volume 14, Issue 5, Pages 367-372.

[21] Jieun Lee, Won Park, Doo Ho Choi, Seung Jae Huh, Im-Ryung Kim, anbee Kang, Juhee Cho. (2017). Patient-reported symptoms of radiation dermatitis during breast cancer radiotherapy: a pilot study July, Volume 26, Issue 7, pp 1713-1719.

[22] Gomes NS, Silva SR. (2013). Avaliação da autoestima de mulheres submetidas à cirurgia oncológica mamária. Texto Contexto Enferm.; 22(3): 509-516.

[23] Bauer, Carole; Laszewski, Pamela; Magnan, Morris: Clinical Journal of Oncology Nursing. Apr2015.

[24] Manne S \& Badr H. (2008): Intimacy and relationship processes in couples' psychosocial adaptation to cancer. Cancer. Jun 1; 112(11 Suppl): 2541-2555. [PMC free article] [PubMed].

[25] Moreira H, Canavarro MC. (2013). Psychosocial adjustment and marital intimacy among partners of patients with breast cancer: A comparison study with partners of healthy women. Journal of psychosocial oncology. 31(3): 282-304. [PubMed].

[26] Julia Sebastián, Dimitra Manos, $\mathrm{M}^{\mathrm{a}}$ José Bueno and Nuria Mateos (2008). Autónoma University of Madrid (Spain). BODY IMAGE AND SELF-ESTEEM IN WOMEN WITH BREAST CANCER PARTICIPATING IN A PSYCHOSOCIAL INTERVENTION PROGRAM, Copyright 2008 by the Psychology in Spain, Vol. 12. No 1, 13-25, Colegio Oficial de Psicologos. Spain.

[27] Carver CS, Pozo-Kaderman C, Price A, Noriega.V, Harris S, Derhagopian RP, Robinson. DS, Moffatt F. (1998). Concern about aspects of body image and adjustment to early stage. breast cancer Psychosom Med; 60:168-74.

[28] Cordova MJ, Cunningham LL, Carlson CR, Andrykowski MA. (2001). Social constraints, cognitive processing and adjustment to breast cancer. J Consul Clin Psychol, 69: 706-11.

[29] Yurek D, Farrar W, Andersen BL. (2000). Breast cancer surgery: ring surgical groups and determining individual differences in postoperative sexuality and body change stress. J Consult Clin Psychol; 68: 697-70. 